\title{
Staphylococcus aureus Putative Vaccines Based on the Virulence Factors: A Mini-Review
}

\author{
Bahman Mirzaei ${ }^{1 *}$, Ryhaneh Babaei ${ }^{1}$, Habib Zeighami ${ }^{1}$, Maryam Dadar ${ }^{2}$ and Ali Soltani ${ }^{3}$ \\ ${ }^{1}$ Department of Medical Microbiology and Virology, School of Medicine, Zanjan University of Medical Sciences, Zanjan, Iran, \\ ${ }^{2}$ Razi Vaccine and Serum Research Institute, Agricultural Research, Education and Extension Organization, Karaj, Iran, \\ ${ }^{3}$ Department of English Language, Zanjan University of Medical Sciences, Zanjan, Iran
}

\section{OPEN ACCESS}

Edited by:

Sanjay Kumar Phogat,

GlaxoSmithKline PLC, Italy

Reviewed by:

Youcef Shahali,

Centre Hospitalier Universitaire

de Besançon, France

Shahzad Ali,

University of Veterinary and Animal

Sciences, Pakistan

*Correspondence:

Bahman Mirzaei

dr.bahman.m@gmail.com:

drbahman@zums.ac.ir

Specialty section:

This article was submitted to Microbial Immunology,

a section of the journal

Frontiers in Microbiology

Received: 02 May 2021

Accepted: 30 July 2021

Published: 03 September 2021

Citation:

Mirzaei B, Babaei R, Zeighami H,

Dadar M and Soltani A (2021)

Staphylococcus aureus Putative Vaccines Based on the Virulence

Factors: A Mini-Review.

Front. Microbiol. 12:704247. doi: 10.3389/fmicb.2021.704247
Since the 1960s, the frequency of methicillin-resistant Staphylococcus aureus as a recurrent cause of nosocomial infections has increased. Since multidrug-resistant Staphylococcus has overcome antimicrobial treatment, the development of putative vaccines based on virulence factors could be a great help in controlling the infections caused by bacteria and are actively being pursued in healthcare settings. This mini-review provides an overview of the recent progress in vaccine development, immunogenicity, and therapeutic features of some S. aureus macromolecules as putative vaccine candidates and their implications against human $S$. aureus-related infections. Based on the reviewed experiments, multivalent vaccines could prevent the promotion of the diseases caused by this bacterium and enhance the prevention chance of $S$. aureus infections.

Keywords: candidate vaccines, immunoprophylaxis, prophylaxis, Staphylococcus aureus, staphylococcal infections Staphylococcus aureus

\section{HIGHLIGHTS}

- Vaccine development against staphylococcal infections is still in its infancy. Irrefutably, more studies on staphylococcal virulence factors and immune evasion are needed to reach a complete understanding of virulence mechanisms.

- Many investigations have put forward a large number of targets for vaccine development against Staphylococcus aureus, which increase the number of putative targets.

- Since numerous changeable infection-related factors exist and are also expressed in staphylococcal species, multivalent vaccines consisting of several antigens related to different infection stages are required.

\section{INTRODUCTION}

Staphylococcus aureus is a widespread commensal and pathogen bacterium. S. aureus bacteria induce staph food poisoning that leads to gastrointestinal illness through eating foods contaminated with the toxins produced. About $25 \%$ of animals and people have staph in their nose and on their skin (Le Loir et al., 2003). It is also one of the most isolated bacteria among both nosocomial and 
community-acquired infections. It causes many types of human infections and syndromes such as mild skin and soft tissue infections, bacteremia, endocarditis, pneumonia, metastatic infections, sepsis, and toxic shock syndrome (van Belkum, 2006). A hospital environment and medical devices contaminated with $S$. aureus can affect the health of patients. Over the past decades, staphylococcus nosocomial infections have significantly increased (Kuklin et al., 2006; Hogea et al., 2014). Since the 1960s when the first methicillin-resistant S. aureus (MRSA) was identified, a major challenge has begun (Adhikari et al., 2012). The emergence of antibiotic-resistant strains of staphylococci, mainly MRSA, emphasizes the serious control of S. aureus-related infections (O'Neill et al., 2008)-for example, the outbreak of S. aureus bloodstream infections in the United States in 2017 induced nearly 20,000 deaths (Kourtis et al., 2019). However, there is no current vaccine for $S$. aureus infection. Several $S$. aureus virulence factors have been evaluated as vaccine candidates. Infections caused by MRSA in hospital wards have decreased due to increased health assessments and the presentation of effective vaccines. Staphylococcus spp. conserved surface components with a high rate of expression in the bloodstream or biofilm-forming process factors stand as suitable staphylococcal candidate vaccines to decrease the staphylococcal disorders (Van Mellaert et al., 2012; Hogea et al., 2014). Thus, it is essential to know the relevant factors involved in biofilm formation from a molecular pathogenesis perspective and to discover the physiological status of these virulence factors within the body in order to realize whether they have the potency to develop an aggressive behavior.

\section{DISCUSSION}

\section{Vaccine Development Based on the Targets}

Many investigations have put forward a large number of targets for vaccine development against $S$. aureus, which increase the number of putative targets. In the classical approach, different targets with certain functions have been studied and evaluated as subunit vaccine. New target candidates have also been suggested by reverse vaccinology and bioinformatics (Zhang et al., 2003; Bowden et al., 2005; Gill et al., 2005). In order to cover the genetic diversity of a pathogen in vaccine development strategies, its pan-genome should be analyzed, and its molecular epidemiology should also be examined (Mora and Telford, 2010).

\section{The Search for Vaccine Targets}

Poly(glutamic acid) (PGA) stands for a good vaccine candidate against the mentioned bacterium, owing to its protection effects against antimicrobial peptides during biofilm-related infections and neutrophil phagocytosis. The result of an experiment indicated that arisen antibodies to conjugated PGA are able to protect three models of animals, including guinea pig, mouse, and rabbit, against anthrax (Joyce et al., 2006).

Phenol-soluble modulins (PSMs) are considered as another promising group as vaccine target. Recently, a study showed that PSM $\beta$ peptides had an inhibitory effect on bacterial dissemination from implants (Rennermalm et al., 2004; Wang et al., 2011). Unlike most mentioned vaccine candidates, PSM $\beta$ interferes the dissemination of biofilm-associated infection via preventing detachment mechanisms.

\section{SOME PUTATIVE VACCINE CANDIDATES TO S. aureus}

\section{Capsular Polysaccharide}

The function of conjugated microencapsulated S. aureus type 8 (the isolate came from bovine mastitis milk) to Pseudomonas aeruginosa exotoxin A (ETA) was assessed in a mouse model. The antibody response was triggered 3 days following the immunization and lasted for 13 days of the observation period after the second injection in some mice. The antibody response and the survival rate were higher in the group of mice immunized with the CP8-ETA conjugates in comparison with those receiving complete Freund's adjuvant or phosphate-buffered saline. Based on the result of this experiment, the CP8-ETA vaccine is able to protect mice against $S$. aureus bacteremia (Han et al., 2000).

\section{Iron-Regulated Surface Determinant B}

The $S$. aureus iron-regulated surface determinant B (IsdB), a prophylactic vaccine against $S$. aureus infection, as an ironsequestering protein exists in many $S$. aureus clinical isolates and methicillin-resistant and methicillin-sensitive isolates and is expressed on the surface of all tested isolates. As the mice were immunized with IsdB formulated with amorphous aluminum hydroxyphosphate sulfate, high immunogenicity of IsdB in rhesus macaques was observed. Furthermore, a fivefold increase in antibody titers was seen after a single immunization, which indicates IsdB potency as a vaccine against $S$. aureus disease in humans (Jones et al., 2001; Kuklin et al., 2006). A randomized study on the preoperative receipt of Merck V710 $S$. aureus vaccine containing non-adjuvanted IsdB demonstrated that all V710 recipients and only about $8 \%$ of the placebo recipients died of postoperative $S$. aureus infection following a major cardiothoracic surgery. These results may raise the concern of researchers about the immunization itself, which might affect either the safety or the efficacy of the development of staphylococcal vaccines (McNeely et al., 2014; Daly et al., 2017). In another cohort study, in spite of modern perioperative management, postoperative S. aureus infection occurred in $1 \%$ of adult patients. The mortality rates were also $3 \%$ for methicillinresistant S. aureus infections and 13\% for MRSA infections (Allen et al., 2014).

\section{Virus-Like Particle-Based Vaccines}

The coordination of the expression of the required virulence factors in the invasive infection of $S$. aureus happens using secreted cyclic auto-inducing peptides (AIPs) and the accessory gene regulator $(a g r)$ operon. AIPs are small in size and require a thiolactone bond. In order to solve this issue, the viruslike particles were utilized as a vaccine platform (PP7) for a conformationally restricted presentation of a modified AIP1 
amino acid sequence (AIP1S). AIP1-specific antibodies inhibited agr activation in vivo; moreover, it reduced pathogenesis and increased bacterial clearance in murine skin and a soft tissue infection model carrying a highly virulent agr type I S. aureus isolate, which all indicated vaccine efficacy and that it might have a great impact on antibiotic resistance (Daly et al., 2017).

TABLE 1 | Some putative vaccine candidates which could be considered in vaccine development against Staphylococcus aureus.

\begin{tabular}{|c|c|c|c|c|}
\hline $\begin{array}{l}\text { Putative } \\
\text { macromolecules }\end{array}$ & Features & Advantage & Disadvantage & References \\
\hline $\begin{array}{l}\text { Polysaccharide intercellular } \\
\text { adhesion (PIA) }\end{array}$ & $\begin{array}{l}\text { Surface polysaccharide } \\
\text { poly-N-acetyl- } \beta \text {-(1-6)-glucosamine } \\
\text { also known as PIA }\end{array}$ & $\begin{array}{l}\text { Produced in vitro by either } \\
\text { S. aureus or Staphylococcus } \\
\text { epidermidis with high levels of } \\
\text { acetate substituting for amino }\end{array}$ & $\begin{array}{l}\text { Immunization with PIA and } \\
\text { other polysaccharides must be } \\
\text { boosted or conjugated to a } \\
\text { safe protein carrier }\end{array}$ & $\begin{array}{l}\text { Maira-Litrán et al., 2005; } \\
\text { Maira-Litrán et al., 2012; Miller } \\
\text { et al., } 2020\end{array}$ \\
\hline
\end{tabular}

Teichoic acid

Accumulation-associated protein

Fibronectin binding protein Presence in S. aureus

A

Virulence factor

Phosphatidylinositol phosphodiesterase
Presence in both $S$. aureus and $S$. epidermidis that plays an essential role in the attachment and aggregation of biofilm phases

(A) Glycerol and ribitol phosphate copolymer by phosphodiester bonds (B) It is assigned as main macromolecule to the primary attachments and accumulation phase in biofilm formation (C) It is chiefly important in inflammation and immune evasion

\section{groups; generate opsonic and} protective antibodies PIA has been extensively evaluated as a putative candidate for vaccine development

One of the main Gram-positive bacteria-adhesive

macromolecules In a study, the efficacy of mAb was determined as $>90 \%$ against CoNS clinical isolates. Up to $90 \%$ of bacterial killing activity was detected at doses $<10 \mu \mathrm{g} / \mathrm{ml}$ as an apt opsonophagocytic result, which prevents related infections in animal models

Polyclonal antibodies inhibit biofilm formation Its conjugation to a confirmed protective polysaccharide, such as PIA, could eliminate the biofilm formation process by inducing cellular immunity-related immunoglobulin subtypes (lgG2a and lgG2b) to activate memory cells

Specific antipeptide immunoglobulin (lg) $\mathrm{G}$ and $\lg \mathrm{A}$ antibodies were detected in the serum and respiratory mucosa of vaccinated mice. Responses to the major pilus backbone protein Spy0128 showed robust antibody responses to this antigen both systemically and in the respiratory and intestinal mucosa

Induce comprehensive cellular and humoral immune responses to reduce bacterial loads, inflammatory cytokine expression, and inflammatory cell infiltration and decrease pathology after challenge with a sub-lethal dose of $S$. aureus

Strong humoral response in the vaccine mice that provided $75 \%$ protection against S. aureus
Arisen antibodies to AaP have no effect on

polysaccharide-dependent

biofilm-forming $S$. aureus and

S. epidermidis

The mechanism(s) of protection Clow et al., 2020 are unclear

No significant differences in lymphocyte subset distribution and serous cytokine levels (IL-4, IL-5, TNF- $\alpha$, IFN- $\gamma$, IL-2, and IL-6) between the vaccine and the placebo groups

Large-scale in vivo studies are called
Ali et al., 2020; van Dalen et al., 2020

Yan et al., 2014

Creech et al., 2020; Zeng et al., 2020; Alabdullah et al., 2021

Soltan et al., 2020 pathogens such as $S$. aureus 


\section{Staphylococcus aureus Alpha-Hemolysin}

Based on the results of previous studies, a recombinant vaccine for $S$. aureus alpha-hemolysin should have a heptameric structure for its crystal. HIa, a pore-forming toxin, is expressed by the majority of $S$. aureus strains. HIa was examined for vaccination with AT-62aa along with a glucopyranosyl lipid adjuvant-stable emulsion. Then, the results indicated that sepsis protection in an experimental model of $S$. aureus infection was done by utilizing Newman and the pandemic strain USA300 (LAC). This model demonstrated the AT-62aa is a proper vaccine candidate. The identification of AT-62aa protective epitopes may also result in novel immunotherapy for $S$. aureus infection (Adhikari et al., 2012).

\section{Staphylococcus aureus LukS-PV-Attenuated Subunit Vaccine}

LukS-mut9 is an attenuated mutant of LukS-PV with a high immunogenic response. This mutant has shown significant protection in mouse sepsis model. Recent findings revealed that the protection of the Panton-Valentine leukocidin (PVL) vaccine in mice model is related tocross-protective responses against other homologous toxins, owing to the generated polyclonal antibodies by LukS-mut9, which can neutralize other canonical and non-canonical leukotoxin pairs. There has been a correlation between the arisen antibodies, PVL subunits, and sepsis in patients with high antibody titer against the mentioned subunits (Adhikari et al., 2012).

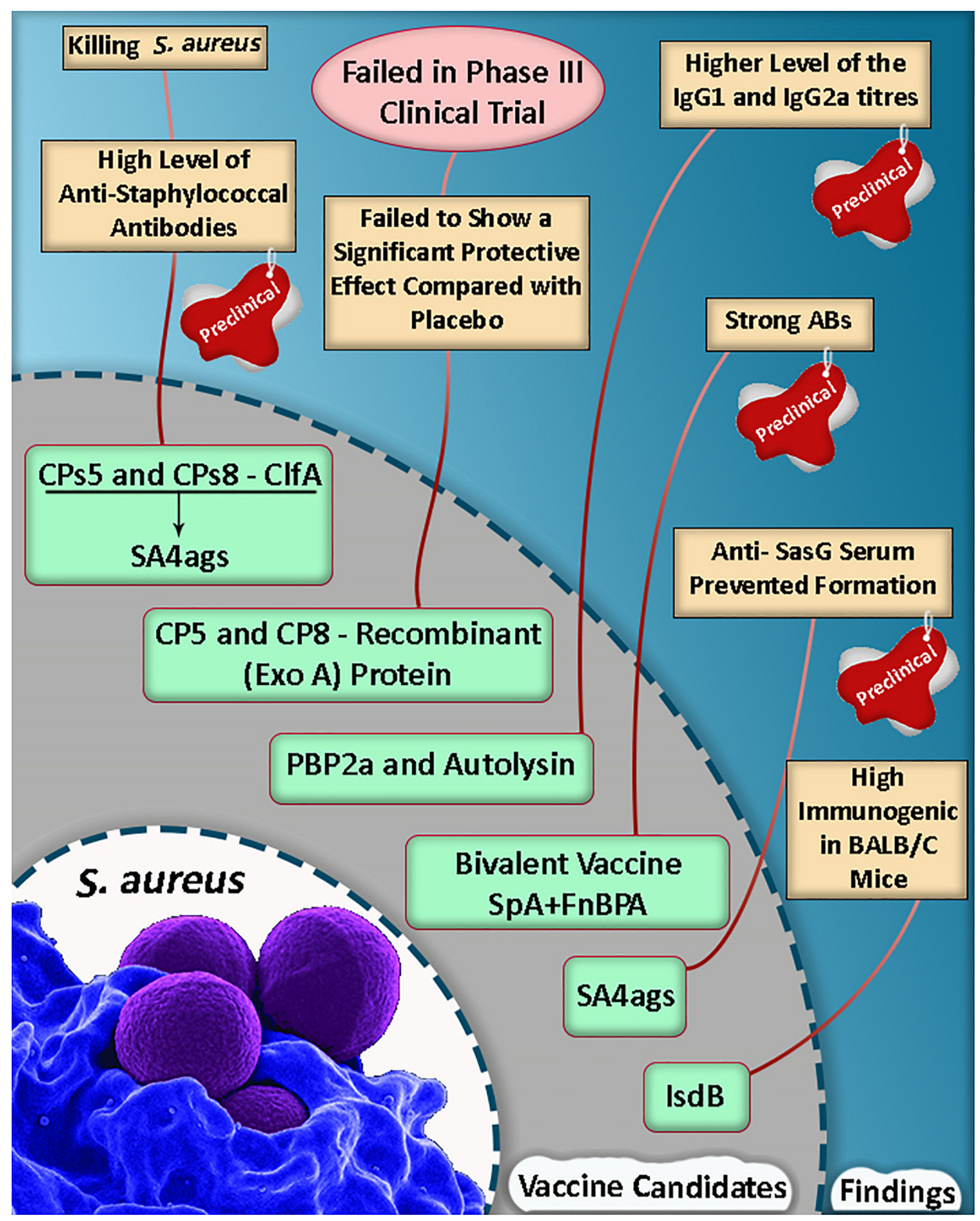

FIGURE 1 | A summary of vaccine candidate development in Staphylococcus aureus (Shinefield et al., 2002; Kuklin et al., 2006; Fowler et al., 2013; Haghighat et al., 2017; Dupont et al., 2018; Yang et al., 2018). 


\section{Four-Component Staphylococcus aureus Vaccine}

In a study conducted based on a murine $S$. aureus infection model, antigen-specific antibodies were accumulated in the pouch, and the infection was mitigated following immunization with 4CStaph and bacterial inoculation in an air pouch generated on the back of the animal. The upregulation of FcR and the presence of antigen-specific antibodies induced by immunization with 4CStaph could increase bacterial opsonophagocytosis. Alternative protection mechanisms may be activated by a proper vaccine, balancing neutropenia, which is a condition often happening to S. aureus-infected patients (Torre et al., 2015).

\section{The Mixture of PBP2a and Autolysin as a Candidate Vaccine Against Methicillin-Resistant S. aureus}

Based on a study, the mortality rate was reduced in mice, and they were protected against lethal MRSA challenge as well as single proteins following an active vaccination with a mixture of $\mathrm{r}$-PBP2a/r-autolysin and a conjugated form of the vaccine (Haghighat et al., 2017). Some of the selective putative vaccine candidates and a summary of the vaccine candidate development in S. aureus are listed in Table $\mathbf{1}$ and Figure $\mathbf{1}$.

\section{LIMITATION}

Several vaccine candidates which are of recent progress in vaccine development are only presented in this study. Therefore, more explanation was not mentioned about the general function of the vaccine candidate molecules, particularly with regard to PSM, ETA, IsdB, alpha-hemolysin, LukS-PV, PBP2a, and autolysin.

\section{CONCLUSION}

Vaccine development against staphylococcal infections is still in its infancy. Irrefutably, more studies on staphylococcal virulence

\section{REFERENCES}

Adhikari, R. P., Karauzum, H., Sarwar, J., Abaandou, L., Mahmoudieh, M., Boroun, A. R., et al. (2012). Novel structurally designed vaccine for S. aureus $\alpha$-hemolysin: protection against bacteremia and pneumonia. PLoS One 7:e38567. doi: 10.1371/journal.pone.0038567

Alabdullah, H. A., Overgaard, E., Scarbrough, D., Williams, J. E., Mohammad Mousa, O., Dunn, G., et al. (2021). Evaluation of the Efficacy of a CholeraToxin-Based Staphylococcus aureus Vaccine against Bovine Intramammary Challenge. Vaccines 9:6. doi: 10.3390/vaccines9010006

Ali, S., Berni, F., Enotarpi, J., Van Der Marel, G. A., and Codée, J. D. (2020). Synthetic teichoic acid chemistry for vaccine applications. Recent Trends Carbohydr. Chem. 2020, 207-238. doi: 10.1016/b978-0-12-820954-7.00006-2

Allen, K. B., Fowler, V. G. Jr., Gammie, J. S., Hartzel, J. S., Onorato, M. T., Dinubile, M. J., et al. (2014). Staphylococcus aureus infections after elective cardiothoracic surgery: observations from an international randomized placebo-controlled trial of an investigational S aureus vaccine. Open Forum Infect. Dis. 1:ofu071.

Bowden, M. G., Chen, W., Singvall, J., Xu, Y., Peacock, S. J., Valtulina, V., et al. (2005). Identification and preliminary characterization of cell-wall-anchored factors and immune evasion are required to enable us to reach a complete understanding of the virulence mechanisms. Since numerous changeable infection-related factors exist and also expressed in staphylococcal species, multivalent vaccines consisting of several antigens related to different infection stages are needed. There are few ways to deal with $S$. aureus infections due to their high antibiotic resistance and also because the infections caused by this microorganism are increasing. However, fortunately, since sufficient research has been done on the effects of various vaccine candidates regarding the S. aureus virulence factor, the capability of biofilm production could be noticed as one of the most important factors in bacterium colonization as well. If a suitable vaccine candidate can be included to (1) inhibit biofilm formation and (2) prevent the effect of bacterial virulence factors, then the possibility of preventing and eliminating infections can be imagined. It is expected that designing a multivalent vaccine with the above-mentioned content will raise the effectiveness of antibodies and lead to the eradication of $S$. aureusrelated infections.

\section{AUTHOR CONTRIBUTIONS}

BM contributed to conceptualization, data collection, data curation, and writing of the manuscript. $\mathrm{RB}, \mathrm{HZ}$, and $\mathrm{MD}$ contributed to data collection. AS contributed to data collection and writing of the manuscript. All authors read and approved the manuscript.

\section{ACKNOWLEDGMENTS}

The authors are grateful to the colleagues in the bacteriology and virology departments at Zanjan University of Medical Sciences for their sincere support. Special thanks go to Dr Mehdi Ghaemi (Department of Anesthesiology, School of Medicine, Zanjan University of Medical Sciences, Zanjan, Iran) for their kind contributions in preparing and final editing of the manuscript.

proteins of Staphylococcus epidermidis. Microbiology 151, 1453-1464. doi: 10.1099/mic.0.27534-0

Clow, F., Peterken, K., Pearson, V., Proft, T., and Radcliff, F. J. (2020). PilVax, a novel Lactococcus lactis-based mucosal vaccine platform, stimulates systemic and mucosal immune responses to Staphylococcus aureus. Immunol. Cell Biol. 98, 369-381. doi: 10.1111/imcb.12325

Creech, C. B., Frenck, R. W., Fiquet, A., Feldman, R., Kankam, M. K., Pathirana, S., et al. (2020). Persistence of immune responses through 36 months in healthy adults after vaccination with a novel Staphylococcus aureus 4 -antigen vaccine (SA4Ag). Open Forum Infect. Dis. 7:ofz532.

Daly, S. M., Joyner, J. A., Triplett, K. D., Elmore, B. O., Pokhrel, S., Frietze, K. M., et al. (2017). VLP-based vaccine induces immune control of Staphylococcus aureus virulence regulation. Sci. Rep. 7:637.

Dupont, C. D., Scully, I. L., Zimnisky, R. M., Monian, B., Rossitto, C. P., O'connell, E. B., et al. (2018). Two Vaccines for Staphylococcus aureus Induce a B-Cell-Mediated Immune Response. mSphere 3, e00217-e00218.

Fowler, V. G., Allen, K. B., Moreira, E. D., Moustafa, M., Isgro, F., Boucher, H. W., et al. (2013). Effect of an investigational vaccine for preventing Staphylococcus 
aureus infections after cardiothoracic surgery: a randomized trial. JAMA 309, 1368-1378. doi: 10.1001/jama.2013.3010

Gill, S. R., Fouts, D. E., Archer, G. L., Mongodin, E. F., Deboy, R. T., Ravel, J., et al. (2005). Insights on evolution of virulence and resistance from the complete genome analysis of an early methicillin-resistant Staphylococcus aureus strain and a biofilm-producing methicillin-resistant Staphylococcus epidermidis strain. J. Bacteriol. 187, 2426-2438.

Haghighat, S., Siadat, S. D., Sorkhabadi, S. M. R., Sepahi, A. A., and Mahdavi, M. (2017). A novel recombinant vaccine candidate comprising PBP2a and autolysin against Methicillin Resistant Staphylococcus aureus confers protection in the experimental mice. Mol. Immunol. 91, 1-7. doi: 10.1016/j. molimm.2017.08.013

Han, H., Pak, S. I., and Guidry, A. (2000). Prevalence of capsular polysaccharide (CP) types of Staphylococcus aureus isolated from bovine mastitic milk and protection of S. aureus infection in mice with CP vaccine. J. Vet. Med. Sci. 62, 1331-1333. doi: $10.1292 /$ jvms.62.1331

Hogea, C., Van Effelterre, T., and Cassidy, A. (2014). A model-based analysis: what potential could there be for a $S$. aureus vaccine in a hospital setting on top of other preventative measures? BMC Infect. Dis. 14:291. doi: 10.1186/1471-233414-291

Jones, S. M., Morgan, M., Humphrey, T. J., and Lappin-Scott, H. (2001). Effect of vancomycin and rifampicin on meticillin-resistant Staphylococcus aureus biofilms. Lancet 357, 40-41. doi: 10.1016/s0140-6736(00)03572-8

Joyce, J., Cook, J., Chabot, D., Hepler, R., Shoop, W., Xu, Q., et al. (2006). Immunogenicity and protective efficacy of Bacillus anthracis poly- $\gamma$-Dglutamic acid capsule covalently coupled to a protein carrier using a novel triazine-based conjugation strategy. J. Biol. Chem. 281, 4831-4843. doi: 10. 1074/jbc.m509432200

Kourtis, A. P., Hatfield, K., Baggs, J., Mu, Y., See, I., Epson, E., et al. (2019). Vital signs: epidemiology and recent trends in methicillin-resistant and in methicillin-susceptible Staphylococcus aureus bloodstream infectionsUnited States. Morb. Mortal. Wkly Rep. 68, 214-219.

Kuklin, N. A., Clark, D. J., Secore, S., Cook, J., Cope, L. D., McNeely, T., et al. (2006). A novel Staphylococcus aureus vaccine: iron surface determinant B induces rapid antibody responses in rhesus macaques and specific increased survival in a murine S. aureus sepsis model. Infect. Immun. 74, 2215-2223. doi: 10.1128/iai.74.4.2215-2223.2006

Le Loir, Y., Baron, F., and Gautier, M. (2003). [i] Staphylococcus aureus [/i] and food poisoning. Genet. Mol. Res. 2, 63-76.

Maira-Litrán, T., Bentancor, L. V., Bozkurt-Guzel, C., O’malley, J. M., CywesBentley, C., and Pier, G. B. (2012). Synthesis and evaluation of a conjugate vaccine composed of Staphylococcus aureus poly-N-acetyl-glucosamine and clumping factor A. PLoS One 7:e43813. doi: 10.1371/journal.pone.0043813

Maira-Litrán, T., Kropec, A., Goldmann, D. A., and Pier, G. B. (2005). Comparative opsonic and protective activities of Staphylococcus aureus conjugate vaccines containing native or deacetylated staphylococcal poly-Nacetyl- $\beta$-(1-6)-glucosamine. Infect. Immun. 73, 6752-6762. doi: 10.1128/iai.73. 10.6752-6762.2005

McNeely, T. B., Shah, N. A., Fridman, A., Joshi, A., Hartzel, J. S., Keshari, R. S., et al. (2014). Mortality among recipients of the Merck V710 Staphylococcus aureus vaccine after postoperative $\mathrm{S}$. aureus infections: an analysis of possible contributing host factors. Hum. Vaccin. Immunother. 10, 3513-3516. doi: 10. 4161/hv. 34407

Miller, L. S., Fowler, V. G. Jr., Shukla, S. K., Rose, W. E., and Proctor, R. A. (2020). Development of a vaccine against Staphylococcus aureus invasive infections: evidence based on human immunity, genetics and bacterial evasion mechanisms. FEMS Microbiol. Rev. 44, 123-153. doi: 10.1093/femsre/fuz030

Mora, M., and Telford, J. L. (2010). Genome-based approaches to vaccine development. J. Mol. Med. 88, 143-147. doi: 10.1007/s00109-0090574-9

O’Neill, E., Pozzi, C., Houston, P., Humphreys, H., Robinson, D. A., Loughman, A., et al. (2008). A novel Staphylococcus aureus biofilm phenotype mediated by the fibronectin-binding proteins, FnBPA and FnBPB. J. Bacteriol. 190, 3835-3850. doi: 10.1128/jb.00167-08
Rennermalm, A., Nilsson, M., and Flock, J.-I. (2004). The fibrinogen binding protein of Staphylococcus epidermidis is a target for opsonic antibodies. Infect. Immun. 72, 3081-3083. doi: 10.1128/iai.72.5.3081-3083.2004

Shinefield, H., Black, S., Fattom, A., Horwith, G., Rasgon, S., Ordonez, J., et al. (2002). Use of a Staphylococcus aureus conjugate vaccine in patients receiving hemodialysis. N. Engl. J. Med. 346, 491-496.

Soltan, M. A., Magdy, D., Solyman, S. M., and Hanora, A. (2020). Design of Staphylococcus aureus New Vaccine Candidates with B and T Cell Epitope Mapping, Reverse Vaccinology, and Immunoinformatics. OMICS 24, 195-204. doi: 10.1089/omi.2019.0183

Torre, A., Bacconi, M., Sammicheli, C., Galletti, B., Laera, D., Fontana, M. R., et al. (2015). Four-component Staphylococcus aureus vaccine 4C-staph enhances $\mathrm{F} c \gamma$ receptor expression in neutrophils and monocytes and mitigates $\mathrm{S}$. aureus infection in neutropenic mice. Infect. Immun. 83, 3157-3163. doi: 10.1128/iai. 00258-15

van Belkum, A. (2006). Staphylococcal colonization and infection: homeostasis versus disbalance of human (innate) immunity and bacterial virulence. Curr. Opin. Infect. Dis. 19, 339-344. doi: 10.1097/01.qco.0000235159.40184.61

van Dalen, R., Peschel, A., and Van Sorge, N. M. (2020). Wall Teichoic Acid in Staphylococcus aureus Host Interaction. Trends Microbiol. 28, 985-998. doi: 10.1016/j.tim.2020.05.017

Van Mellaert, L., Shahrooei, M., Hofmans, D., and Eldere, J. V. (2012). Immunoprophylaxis and immunotherapy of Staphylococcus epidermidis infections: challenges and prospects. Expert Rev. Vaccin. 11, 319-334. doi: 10.1586/erv.11.190

Wang, R., Khan, B. A., Cheung, G. Y., Bach, T. H., Jameson-Lee, M., Kong, K. F., et al. (2011). Staphylococcus epidermidis surfactant peptides promote biofilm maturation and dissemination of biofilm-associated infection in mice. J. Clin. Invest. 121, 238-248.

Yan, L., Zhang, L., Ma, H., Chiu, D., and Bryers, J. D. (2014). A single B-repeat of Staphylococcus epidermidis accumulation-associated protein induces protective immune responses in an experimental biomaterialassociated infection mouse model. Clin. Vaccin. Immunol. 21, 1206-1214. doi: 10.1128/cvi.00306-14

Yang, L., Zhou, H., Cheng, P., Yang, Y., Tong, Y., Zuo, Q., et al. (2018). A novel bivalent fusion vaccine induces broad immunoprotection against Staphylococcus aureus infection in different murine models. Clin. Immunol. 188, 85-93. doi: 10.1016/j.clim.2017.12.012

Zeng, H., Yang, F., Feng, Q., Zhang, J., Gu, J., Jing, H., et al. (2020). Rapid and Broad Immune Efficacy of a Recombinant Five-Antigen Vaccine against Staphylococcus aureus Infection in Animal Models. Vaccines 8:134. doi: 10. 3390/vaccines8010134

Zhang, Y. Q., Ren, S. X., Li, H. L., Wang, Y. X., Fu, G., Yang, J., et al. (2003). Genome-based analysis of virulence genes in a non-biofilm-forming Staphylococcus epidermidis strain (ATCC 12228). Mol. Microbiol. 49, 15771593. doi: $10.1046 /$ j.1365-2958.2003.03671.x

Conflict of Interest: The authors declare that the research was conducted in the absence of any commercial or financial relationships that could be construed as a potential conflict of interest.

Publisher's Note: All claims expressed in this article are solely those of the authors and do not necessarily represent those of their affiliated organizations, or those of the publisher, the editors and the reviewers. Any product that may be evaluated in this article, or claim that may be made by its manufacturer, is not guaranteed or endorsed by the publisher.

Copyright $\odot 2021$ Mirzaei, Babaei, Zeighami, Dadar and Soltani. This is an openaccess article distributed under the terms of the Creative Commons Attribution License (CC BY). The use, distribution or reproduction in other forums is permitted, provided the original author(s) and the copyright owner(s) are credited and that the original publication in this journal is cited, in accordance with accepted academic practice. No use, distribution or reproduction is permitted which does not comply with these terms. 